\title{
Mechanical Response of Al-1.09Mg 2 Si Alloy under Varying Mould and Thermal Ageing Conditions
}

\author{
O. I. Sekunowo, G. I. Lawal, and S. O. Adeosun \\ Department of Metallurgical and Materials Engineering, Faculty of Engineering, University of Lagos, Lagos 101017, Nigeria \\ Correspondence should be addressed to O. I. Sekunowo, olatundeisrael@yahoo.co.uk
}

Received 23 August 2012; Revised 12 November 2012; Accepted 16 November 2012

Academic Editor: Gerhard Sauthoff

Copyright () 2012 O. I. Sekunowo et al. This is an open access article distributed under the Creative Commons Attribution License, which permits unrestricted use, distribution, and reproduction in any medium, provided the original work is properly cited.

Samples of the $6063\left(\mathrm{Al}-1.09 \mathrm{Mg}_{2} \mathrm{Si}\right.$ ) alloy ingot were melted in a crucible furnace and cast in metal and sand moulds, respectively. Standard tensile, hardness, and microstructural test specimens were prepared from cast samples, solution treated at $520^{\circ} \mathrm{C}$, soaked for $6 \mathrm{hrs}$, and immediately quenched at ambient temperature in a trough containing water to assume a supersaturated structure. The quenched specimens were then thermally aged at $175^{\circ} \mathrm{C}$ for $3-7 \mathrm{hrs}$. Results show that at different ageing time, varied fractions of precipitates and intermetallics evolved in the specimens' matrices which affect the resulting mechanical properties. The metal mould specimens aged for four hours (MTA-4) exhibited superior ultimate tensile strength of $247.8 \mathrm{MPa}$; microhardness, $68.5 \mathrm{HV}$; elongation, $28.2 \%$. It is concluded that the extent of improvement in mechanical properties depends on the fractions, coherence, and distribution of precipitates along with the type of intermetallics developed in the alloy during ageing process.

\section{Introduction}

Casting is one of the most versatile methods of producing structural aluminium alloy components. However, the rather large preponderance of defects in cast aluminium components often limits their performance and adversely impacts their commercial values. Hence there is the need for a novel processing approach to improve the cast microstructure for enhanced performance. Generally, the poor mechanical properties of cast aluminium alloys can be improved through either alloy addition or various forms of heat treatment [1]. During the heat treatment of cast aluminium alloys, an advantage is made of the characteristic decrease in solubility at low temperature of magnesium $(\mathrm{Mg})$ and silicon $(\mathrm{Si})$ which are the main alloying elements in $\mathrm{Al}-\mathrm{Mg}-\mathrm{Si}$ alloy. Further, Keist [2] confirms that the appreciable decrease in concentration of the alloying elements at room temperature is the fundamental phenomenon that provides the basis for increasing substantially the hardness and strength of aluminium alloys through isothermal treatment.

Similarly, Siddiqui et al. [3] have shown that improved ductility can be achieved by process annealing at $415^{\circ} \mathrm{C}$, soaked between two and three hours coupled with a cooling rate $30^{\circ} \mathrm{C}$ per hour.

Generally, strength improvement of most 6063 aluminium alloys can be effected in a three-pronged approach comprising solution heat treatment, quenching, and precipitation of solute atoms [4]. However, the greatest challenge usually encountered with this approach is effective control of the second-phase precipitates. Lumley et al. [5] proposed a method known as interrupted ageing for effective control and exploitation of secondary precipitation to improve the mechanical properties of aluminium alloys. This method promotes nucleation of finely dispersed precipitates in the final microstructure. Consequently, it was possible to achieve an average increase in $0.2 \%$ proof stress of $10-15 \%$ coupled with improved fracture toughness. This development underscores the effect of ageing conditions on the mechanical behaviours of the 6063 (Al-Mg-Si) alloy.

Gao et al. [6] investigated the influence of ageing conditions on the microstructure and tensile strength of $6063 \mathrm{alu}-$ minum alloy. Both temperature and soaking time were varied in the range $165^{\circ} \mathrm{C}-288^{\circ} \mathrm{C}$ at 25 and 64 hours, respectively. The results show that the higher the ageing temperature, the 
shorter time it takes to reach peak strength. Precipitation of secondary phase structures and its distribution within the matrix also play a major role in determining changes in mechanical properties of aluminium alloy [7]. It is therefore reasonable to leverage this possibility of microstructural manipulations for desirable property changes to achieve improved mechanical characteristics.

It has also been established that factors that determine the mechanical behaviours of a 6063 aluminium alloy component are the type, amount, and distribution of secondphase particles such as $\mathrm{Mg}_{2} \mathrm{Si}, \mathrm{Al}-\mathrm{Fe}, \mathrm{Al}-\mathrm{Fe}-\mathrm{Si}$, and $\mathrm{Al}-\mathrm{Fe}-$ $\mathrm{Mn}-\mathrm{Si}$ dissolved in solution [8]. However, according to Tsao et al. [9], the phases that formed eventually depend mainly on the cooling rate and the Fe/Si ratio in the alloy. The combination of manganese with $\mathrm{Fe}, \mathrm{Si}$, and $\mathrm{Al}$ also forms $\alpha$ $\mathrm{Al}_{x}(\mathrm{Fe}, \mathrm{Mn})_{y} \mathrm{Si}_{z}$ phase that acts as nucleation sites for $\mathrm{Mg}_{2} \mathrm{Si}$ and other crystals, which eventually influences the alloys behaviour [10]. Manganese as a common addition in 6XXX alloys increases strength as finely precipitated intermetallics modify the shape of plate-like iron phases which reduces their tendency to embrittlement [11].

The profound ability of 6063 aluminium alloys strengthening through precipitation hardening for industrial applications remains a major breakthrough in the field of materials processing [12]. Hence, precipitation hardened aluminium alloys are a commercially important group of materials because their mechanical properties can be modified by heat treatment.

However, the imperative of achieving a sufficient fraction of stable precipitates with appropriate morphology and their homogeneous dispersion within the matrix has been a major challenge. This underscores the need to develop a processing method that is capable of inducing in the alloy such desirable microstructural features that confer improved mechanical properties. Consequently, this work examines the mechanical response of $6063\left(\mathrm{Al}-1.09 \mathrm{Mg}_{2} \mathrm{Si}\right)$ alloy processed through varying moulds and thermal ageing conditions.

\section{Experimental Procedure}

2.1. Material, Specimen Preparation, and Heat Treatment. Three kilogrammes $(3 \mathrm{~kg})$ of 6063 aluminium alloy ingot used for this study were obtained from the Nigerian Aluminium Extrusion Company (NIGALEX) Lagos, Nigeria, and its chemical composition is presented in Table 1. The ingot was sized into smaller pieces, charged into a pretreated low-pour-fuel-oil (LPFO) fired crucible furnace, and allowed to melt at slightly above $660^{\circ} \mathrm{C}$. Metal and sand moulds of dimension, $15 \times 146 \mathrm{~mm}$, respectively, were prepared using a solid cylindrical wooden pattern of $D 15 \mathrm{~mm}$ and $350 \mathrm{~mm}$ long. Four (4) samples each were cast in the metal and sand moulds, allowed to cool, and removed afterwards. With the aid of a hacksaw (manual) at ambient temperature, samples from both moulds were milled into twelve pieces and machined to standard tensile and microhardness test specimens. These were grouped into two and identified as presented in Table 2 . The specimens were then solution heat treated in a muffle furnace model $\mathrm{L} 40 / 11 \mathrm{~B} 170$ at $520^{\circ} \mathrm{C}$ and soaked for six hours. They were immediately quenched in a trough containing water that was maintained at ambient temperature $\left(36-39^{\circ} \mathrm{C}\right)$. The specimens were then thermally aged at $175^{\circ} \mathrm{C}$ for $3-7$ hours.

2.2. Microstructure Analysis. Both the as-cast and thermally aged specimens prepared from metal and sand mould cast samples were ground in succession using emery paper of grits in the range of 220 to 600 microns. Each specimen surface was thereafter polished using aluminium-diamond paste under running water until a mirror-like surface was obtained. Microstructural examination of the specimens was carried out after their polished surfaces had been etched for $20 \mathrm{~s}$ using $1 \mathrm{~g}$ of sodium hydroxide $(\mathrm{NaOH})$ in $100 \mathrm{~mL}$ of water. The specimen microstructural features were then viewed under an optical metallurgical microscope at a magnification of $\times 200$, and the micrographs are presented in Figures 1(a)-1(f) and Figures 2(a)-2(f).

2.3. Mechanical Properties Evaluation. Standard tensile test specimens prepared from the as-cast, and thermally aged (MTA-i and STA-i) samples were subjected to tensile test using an Instron electromechanical machine model 3369. The microhardness values of both test specimens were also evaluated using a Leco Vicker micro hardness tester model LMT700AT under $100 \mathrm{~g}$ test load and at a dwelling time of 10 seconds. The specimen microhardness values (average) were obtained in three readings, namely, at the centre and adjacent vertices of the specimen surfaces.

\section{Results and Discussion}

Results of the ultimate tensile strength (UTS), ductility, and microhardness responses by test specimens are illustrated in Figures 3-9, while the microstructures induced in the test specimens are shown in Figures 1 and 2.

3.1. Microstructure. The micrographs in Figure 1 show the as-cast microstructure of the aluminium alloy (Figure 1(a)) displaying a near monolithic alpha aluminium matrix interspersed with low fraction of plate-like $\mathrm{Mg}_{2} \mathrm{Si}$ precipitates, microsegregations, and inclusions. Given the relatively fast cooling of cast in a metal mould, microsegregation is normally not a common occurrence but for the presence of inclusions which aid its formation. The microstructure in Figure 1(a) is therefore typical of 6063 aluminium alloy ingot structure in its untreated condition.

On subjecting the specimens to a combined process of solution heat treatment and thermal ageing for varying periods of time, the specimens experienced various remarkable microstructural transformations. Figures 1(b)1(f) reveal microstructures of the solution heat treated and thermally aged metal mould cast specimens. The micrograph in Figure 2(b) shows very low fractions of $\mathrm{Mg}_{2} \mathrm{Si}$ precipitates developed after three hours of ageing. Moreover, the precipitates are not homogeneously dispersed within the alpha aluminium matrix. As the ageing period progressed up to four hours (Figure 2(c)), decomposition of the as-quenched structure continued and culminated in the formation of 
TABLE 1: Chemical composition of as-received $6063\left(\mathrm{Al}-1.09 \mathrm{Mg}_{2} \mathrm{Si}\right)$ alloy ingot.

\begin{tabular}{lcccccccccc}
\hline Element & $\mathrm{Mg}$ & $\mathrm{Si}$ & $\mathrm{Mn}$ & $\mathrm{Cu}$ & $\mathrm{Zn}$ & $\mathrm{Ti}$ & $\mathrm{Fe}$ & $\mathrm{Ca}$ & $\mathrm{Cr}$ & $\mathrm{Al}$ \\
\hline Composition (wt\%) & 0.482 & 0.441 & 0.123 & 0.001 & 0.004 & 0.012 & 0.199 & 0.001 & 0.001 & 98.736 \\
\hline
\end{tabular}

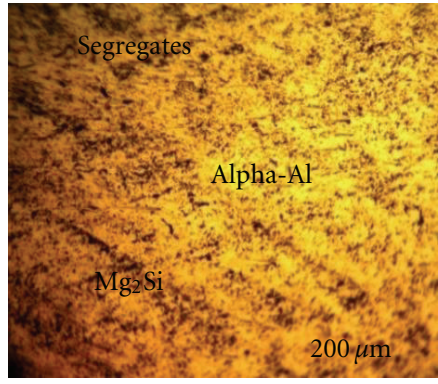

(a) Mcast

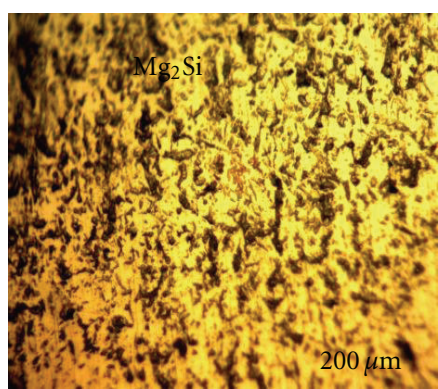

(d) MTA-5

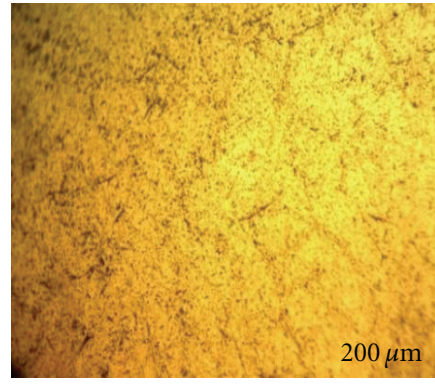

(b) MTA-3

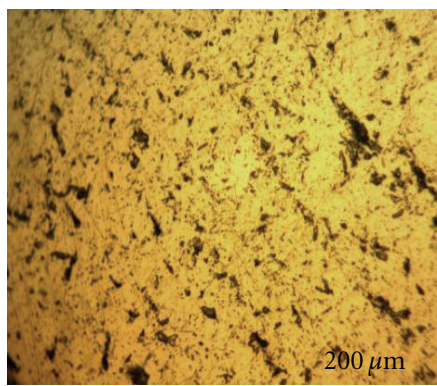

(e) MTA-6

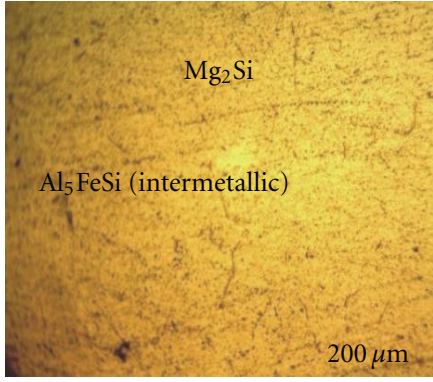

(c) MTA-4

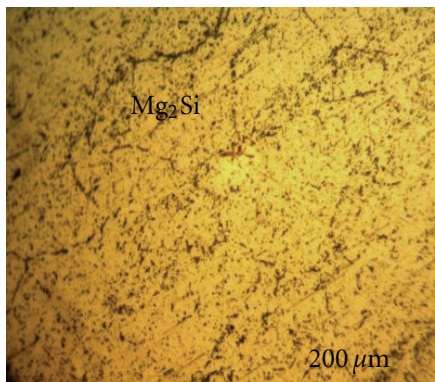

(f) MTA-7

Figure 1: Micrographs of metal mould cast specimens: (a) as-cast, (b) solution treated and aged for 3 hrs, (c) solution treated and aged for $4 \mathrm{hrs}$, (d) solution treated and aged for 5 hrs, (e) solution treated and aged for 6 hrs and (f) solution treated and aged for 7 hrs.

TABLE 2: Specimens identification system.

\begin{tabular}{|c|c|}
\hline Notation & Description \\
\hline Mcast & Cast in metal mould \\
\hline Scast & Cast in sand mould \\
\hline STA- $i$ & $\begin{array}{l}\text { Cast in sand mould, solution treated and thermally } \\
\text { aged for " } i \text { " time ( where " } i \text { " is from 3-7 hours.) }\end{array}$ \\
\hline MTA- $i$ & $\begin{array}{l}\text { Cast in metal mould, solution and thermally aged for } \\
\text { " } i \text { " time ( where " } i \text { " is from } 3-7 \text { hours.) }\end{array}$ \\
\hline
\end{tabular}

substantial fractions of fine needle-like (fibrous) $\mathrm{Mg}_{2} \mathrm{Si}$ precipitates along with other intermetallics which include $\mathrm{Al}_{5} \mathrm{FeSi}$ and $\mathrm{Al}_{12}(\mathrm{FeMn})_{3} \mathrm{Si}$ in consonance with the alloy composition (see Table 1). The precipitates are coherent and homogeneously dispersed within the alpha aluminium matrix. Coarse $\mathrm{Mg}_{2} \mathrm{Si}$ precipitates and other intermetallics are seen in Figure 2(d). The growth of the crystals may be attributed to the period (five hours) within the $\mathrm{Mg}_{2} \mathrm{Si}$ precipitates suffered coarsening due to an overaging treatment. This feature is absent in Figures 2(e) and 2(f) where dissolution of precipitates and clustering prevailed at six and seven hours of ageing, respectively. This agrees well with the work of Tsao et al. [9], which shows that the rate of microstructure transformation in Al-Mg-Si alloy that precipitates from metastable to stable phase is influenced by time.
Hence, in the present study, it is observed that the amount, size, and morphology of precipitates change with time. However, this is a descriptive analysis of the test specimens' microstructures as observed under an optical microscope. Further, the issue of precipitate stability during ageing is of great concern in 6063 aluminium alloys. It is established [11] that the presence of iron $(\mathrm{Fe})$ in excess of certain concentrations has the tendency of exerting preferential stability of the precipitates. Consequently, the presence of $\mathrm{Fe}$, which is about $0.199 \mathrm{wt} \%$ (see Table 1), in the Al-Mg-Si alloy under investigation is capable of skewing the amount of stable precipitates in favour of $\mathrm{Mg}_{2} \mathrm{Si}$.

Micrographs of the sand mould cast specimens are shown in Figures 2(a)-2(f). It is observed in Figure 2(a) that the fractions of coarse $\mathrm{Mg}_{2} \mathrm{Si}$ precipitates are quite low, while the amount of microsegregates appears rather high and large in size compared with similar segregates in Figure 1(b). This can be attributed to the disparity in mould conditions as it affects the cast solidification rate. Figure 2(b) shows a predominantly alpha aluminium matrix with very low fractions of second-phase precipitates. However, when ageing time increased to four hours, plate-like crystals of $\mathrm{Mg}_{2} \mathrm{Si}$ are strongly precipitated and evenly dispersed within the matrix (Figure 2(c)).

The fibrous $\mathrm{Mg}_{2} \mathrm{Si}$ crystals that precipitated after five hours of ageing appear clustered along the grain boundaries and incoherent with the parent aluminium matrix 


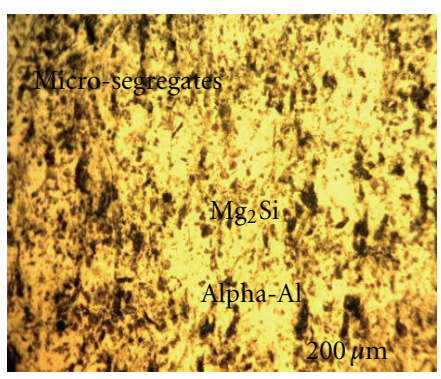

(a) Scast

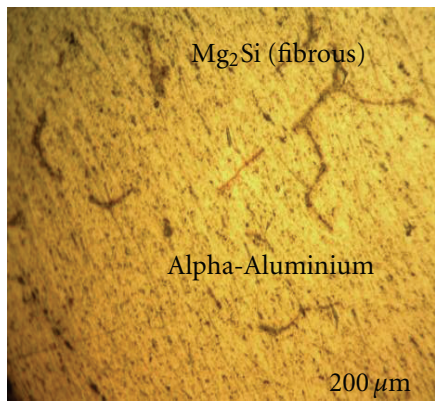

(d) STA-5

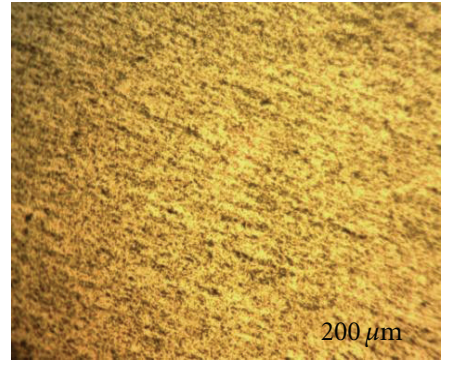

(b) STA-3

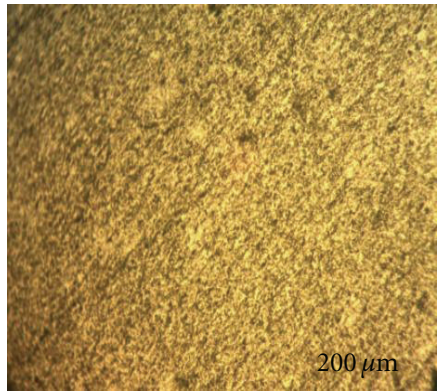

(e) STA-6

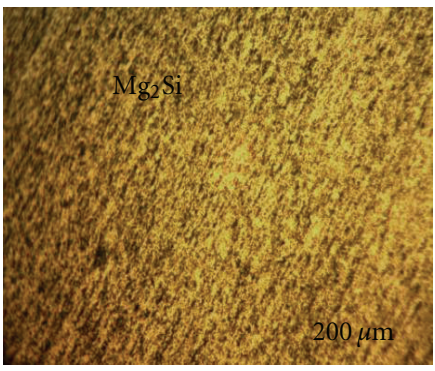

(c) STA-4

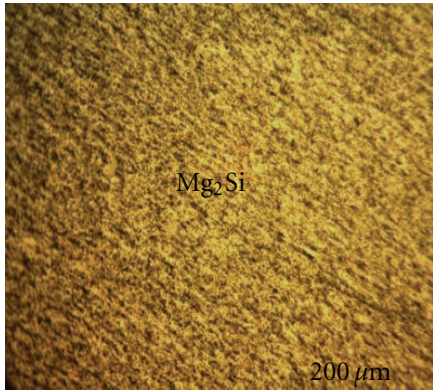

(f) STA-7

FIGURE 2: Micrographs of sand mould cast specimens: (a) as-cast, (b) solution treated and aged for 3 hrs, (c) solution treated and aged for $4 \mathrm{hrs}$, (d) solution treated and aged for $5 \mathrm{hrs}$, (e) solution treated and aged for 6 hrs and (f) solution treated and aged for $7 \mathrm{hrs}$.

(Figure 2(d)). This feature is absent in Figure 2(e) due to the presence of strongly precipitated second phase. However, the process of structure reversion beyond six hours of ageing (Figure 2(f)) is a stop gap for the nucleation of new crystals from the old unstable phase as a precursor to coarsening of $\mathrm{Mg}_{2} \mathrm{Si}$ precipitates.

3.2. Ultimate Tensile Strength. Figure 3 illustrates the ultimate tensile strength (UTS) behaviour of both the as-cast specimens (Mcast and Scast) compared with the solution heat treated and thermally aged for three hours (MTA-3 and STA-3) specimens. It is evident from Figure 3 that the MTA-3 specimen exhibited the highest UTS of $193.8 \mathrm{MPa}$, while the Scast has the least UTS value $72.4 \mathrm{MPa}$. The huge difference in tensile values is attributable to the presence of the reinforcing fractions of $\mathrm{Mg}_{2} \mathrm{Si}$ precipitates in the MTA-3 microstructure (Figure 1(b)) compared with the monolithic alpha aluminium structure of the Scast specimen (Figure 2(a)). However, both the Scast and STA-3 specimens demonstrated comparable UTS values of $72.4 \mathrm{MPa}$ and 81.1 MPa, respectively, due to their similar microstructural features.

The results of ageing time on the 6063 aluminium alloy demonstrate marked effect with regard to the MTA-4 specimen UTS value of $247.8 \mathrm{MPa}$ as observed in Figure 4 . This is predicated on the stable fine needle-like $\mathrm{Mg}_{2} \mathrm{Si}$ precipitates coupled with the presence of hard intermetallics induced by the presence of iron in the alloy composition (see Table 1 and Figure 1(c)).

Needle-like $\mathrm{Mg}_{2} \mathrm{Si}$ precipitates have the ability to form effective network of resistance to dislocations motion within the structure, hence the marked increase in UTS compared

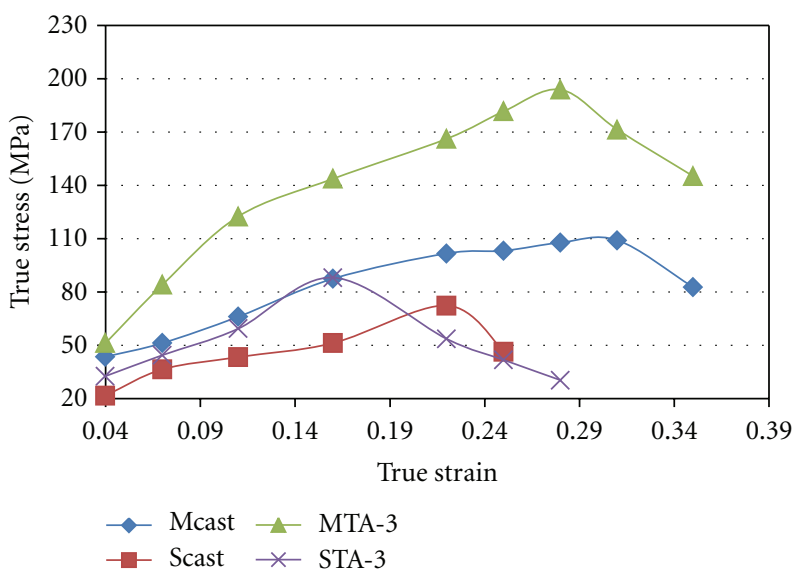

FIGURE 3: Variation of true stress-strain of as-cast metal and sand mould specimens after three hours of ageing.

with 107.3 MPa of STA-4 due to its structure which is grossly deficient in fine needle-like precipitates (Figure 2(c)). These observations perfectly support the findings of [11] in relation to the effect of the combined presence of stable and hard intermetallics on tensile response of aged 6063 aluminium alloy. It is also evident in Figures 5, 6, and 7 that the thermally aged specimen UTS values decrease drastically under varying mould conditions as the ageing time increases from 5-7 hours in the following order: MTA-5, 148.2 MPa (STA-5, 82.8 MPa), MTA-6, 106.1 MPa (STA-6, 73.5 MPa), and MTA7, 93.1 MPa (STA-7, 61.5 MPa). 


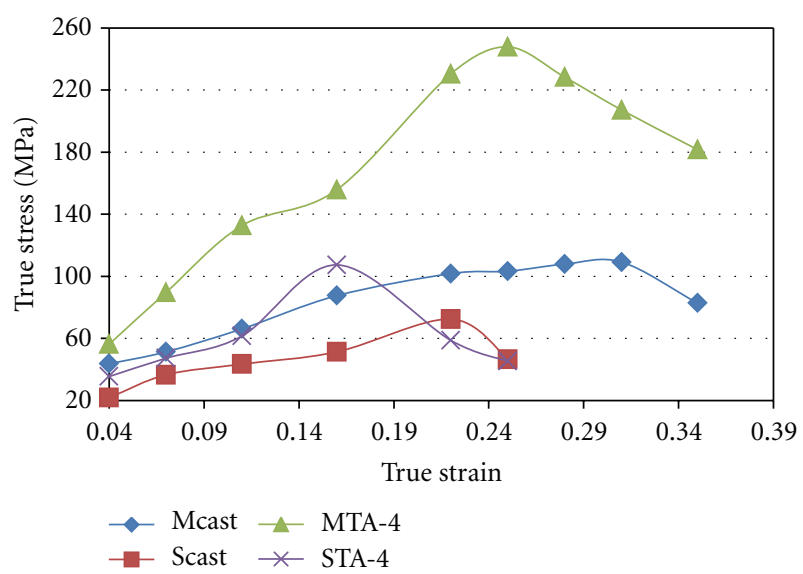

FiguRE 4: Variation of true stress-strain of as-cast metal and sand mould specimens after four hours of ageing.

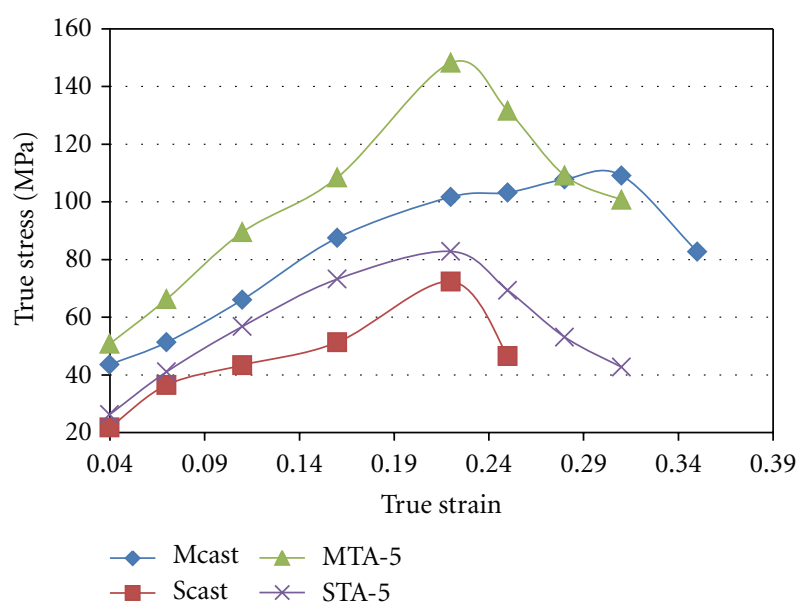

FIGURE 5: Variation of true stress-strain of as-cast metal and sand mould specimens after five hours of ageing.

The progressive decrease in UTS is due to the reduction in weight fraction of reinforcing $\mathrm{Mg}_{2} \mathrm{Si}$ crystals and $\mathrm{Al}_{5} \mathrm{FeSi}$ and $\mathrm{Al}_{12}(\mathrm{FeMn})_{3} \mathrm{Si}$ intermetallics. As ageing time increases from 5-7 hours, the precipitates induced become unstable and incoherent in particular; the intermetallics formed increased in fraction and exhibit such characteristics that make them fracture easily under tensile force. This further validates the earlier work of Chennakesava and Zitoun [13] in which it is reported that the UTS of aged 6063 aluminium alloy decreases with larger fractions of the presence of iron forming intermetallics in its matrix.

Similar trends of progressive reduction in UTS values were demonstrated by the STA-5, 6, 7 specimens which correspond to the extent of precipitate coarsening and their heterogeneous dispersion within the matrix. As shown in Figure 7, both the as-cast and thermally aged for seven hours specimens exhibited close UTS values, namely, Mcast, 109.1 MPa, Scast, 72.1 MPa, MTA-7, 93.1 MPa, STA-7, and 61.5 MPa. In each of these instances, the influence of mould conditions coupled with varying ageing time appears to have

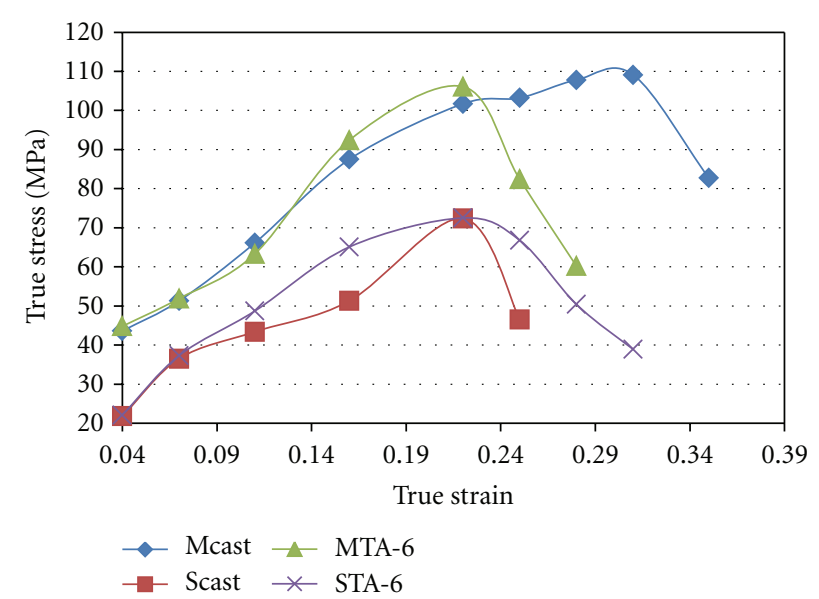

FIGURE 6: Variation of true stress-strain of as-cast metal and sand mould specimens after six hours of ageing.

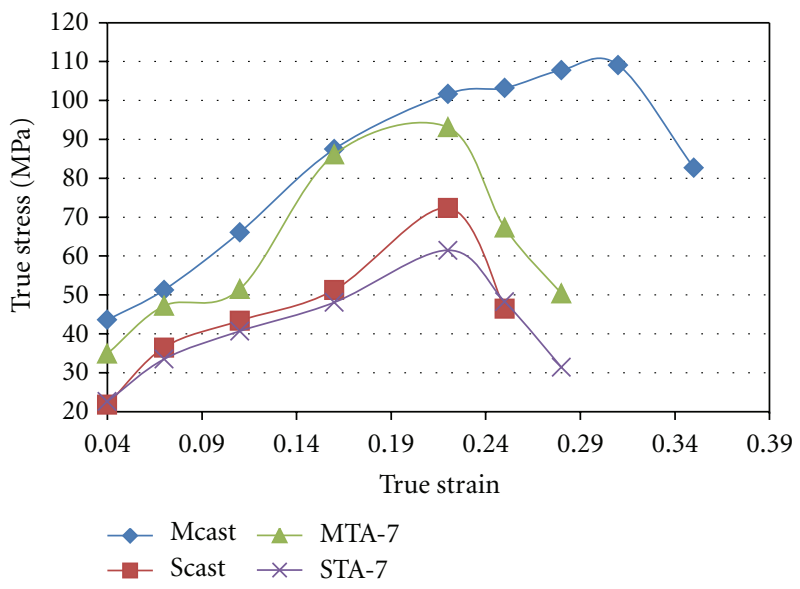

Figure 7: Variation of true stress-strain of as-cast metal and sand mould specimens after seven hours of ageing.

been subdued. This is attributable to the structural similarity of the specimens as shown in Figures 1(d)-1(f) and 2(d)$2(\mathrm{f})$ occasioned by the few coarse and incoherent precipitates induced within their matrices.

3.3. Ductility. Presented in Figure 8 are the results of the alloy ductility behaviour at different mould conditions under varying ageing time. Generally, the ductility response of both the metal and sand cast specimens exhibits a similar trend at varying ageing time.

This is attributable to the progressive reduction with ageing time, the weight fractions of reinforcing $\mathrm{Mg}_{2} \mathrm{Si}$ precipitates, and their replacement with coarse and incoherent ones along with iron forming intermetallics $\left(\mathrm{Al}_{5} \mathrm{FeSi}\right.$ and $\mathrm{Al}_{12}(\mathrm{FeMn})_{3} \mathrm{Si}$ ) which enhance ductility (see Figures $1(\mathrm{~d})$ $1(\mathrm{f})$ and Figures $2(\mathrm{~d})-2(\mathrm{f})$ ).

However, compared with the sand cast specimen ductility which is in the range of $15.9-24.5 \%$, the metal cast specimens show better ductility in the range of $19.4-35.7 \%$. It is normally required that cast structural components possess 


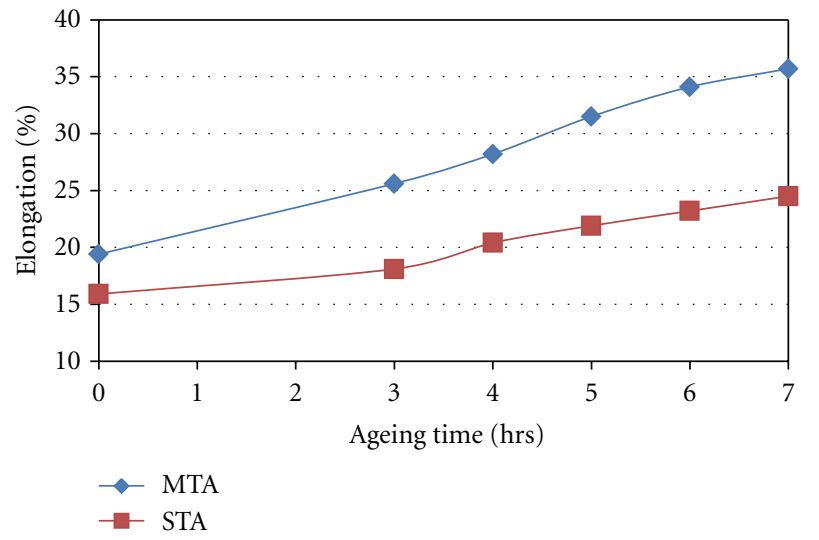

FIGURE 8: Variation of specimens' ductility with ageing time.

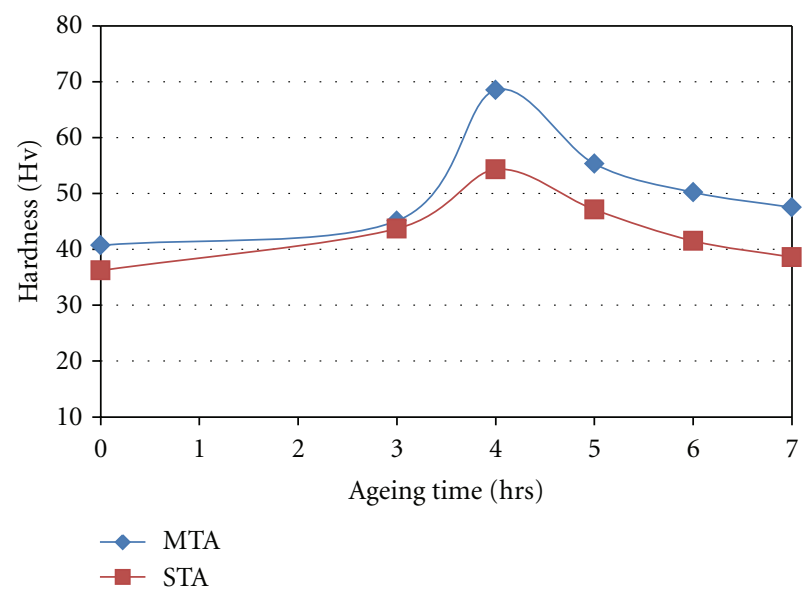

FIGURE 9: Variation of specimens' microhardness with ageing time.

certain level of ductility for enhanced formability. This can only be achieved through innovative processing such as friction stir casting of AA6063- $\mathrm{T}_{6}$ employed by Karthikeyan and Senthil Kumar [14] that exhibited an increase of 133\% ductility in relation to the parent material. The $28.2 \%$ ductility exhibited by the metal cast and thermally aged for four hours (MTA-4) specimen compared well with 14\%

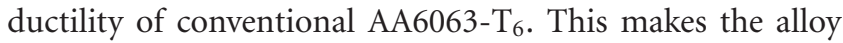
relatively suitable for structural applications.

3.4. Microhardness. The effects of both varying mould conditions and ageing time on the microhardness developed in the test specimens are shown in Figure 9. In both conditions, the microhardness values of the as-cast specimens in metal and sand moulds are the least, Mcast: $40.7 \mathrm{HV}$ and Scast: $36.2 \mathrm{HV}$. This is predicated on the low fraction of fine platelike crystals of $\mathrm{Mg}_{2} \mathrm{Si}$ crystals and microsegregates within the matrix of the Mcast structure (see Figure 1(a)). Similarly, the Scast low hardness is due to the scanty coarse plate-like $\mathrm{Mg}_{2} \mathrm{Si}$ crystals and large fraction of microsegregates in its structure (see Figure 2(a)). However, the precipitation of fine needlelike $\mathrm{Mg}_{2} \mathrm{Si}$ crystals and coherent iron forming intermetallics from the onset of ageing gave rise to an increase in hardness until the peak value of $68.5 \mathrm{HV}$ and $54.3 \mathrm{HV}$ for the MTA4 and STA-4 specimens, respectively. It is also observed in Figure 9 that a decline in microhardness sets in as ageing time increases beyond four hours due to precipitate coarsening and the presence of more $\mathrm{Al}_{12}(\mathrm{FeMn})_{3} \mathrm{Si}$ intermetallics that are incoherent with the alpha aluminium matrix. This type of structure often induces porosity in the alloy microstructure which impairs microhardness.

\section{Conclusion}

In this study, the fractions, morphology, and dispersion of $\mathrm{Mg}_{2} \mathrm{Si}$ and the type of intermetallics $\left(\mathrm{Al}_{5} \mathrm{FeSi}\right.$ and $\mathrm{Al}_{12}(\mathrm{FeMn})_{3} \mathrm{Si}$ ) developed in test specimens through thermal ageing significantly influenced their mechanical properties. Further, the ageing time impacted both the morphology and stability or otherwise of the precipitates. The highest UTS of 247.8 MPa compared with $195 \mathrm{MPa}$ of conventional AA6063$\mathrm{T}_{6}, 28.2 \%$ ductility against $14 \%$ of standard AA6063- $\mathrm{T}_{6}$, and a modest microhardness of $68.5 \mathrm{HV}$ were all obtained through the MTA-4 treatment. This is the only process route that demonstrated improved balanced mechanical properties in the metal cast and thermally aged Al- $1.09 \mathrm{Mg}_{2} \mathrm{Si}$ alloy. The mechanical characteristics developed in the alloy through the MTA- 4 process route have demonstrated the alloy suitability for structural applications coupled with the ability to withstand excessive wear in service.

\section{References}

[1] R. A. Siddiqui, H. A. Abdullah, and K. R. Al-Belushi, "Influence of aging parameters on the mechanical properties of 6063 aluminium alloy," Journal of Materials Processing Technology, vol. 102, no. 1, pp. 234-240, 2000.

[2] J. Keist, "The development of a fluidized bed process for the heat treatment of aluminum alloys," Journal of Materials, vol. 57, no. 4, pp. 34-39, 2005.

[3] R. A. Siddiqui, S. A. Abdul-Wahab, and T. Pervez, "Effect of aging time and aging temperature on fatigue and fracture behavior of 6063 aluminum alloy under seawater influence," Materials and Design, vol. 29, no. 1, pp. 70-79, 2008.

[4] W. Callister, Materials Science and Engineering: An Introduction, John Wiley and Sons, Clementi Loop, Singapore, 6th edition, 2006.

[5] R. N. Lumley, I. J. Polmear, and A. J. Morton, "Control of secondary precipitation to improve the performance of aluminium alloys," Materials Science Forum, vol. 396-402, no. 2, pp. 893-898, 2002.

[6] R. Q. Gao, K. Stiller, V. Hansen, A. Oskarsson, and F. Danoix, "Influence of aging conditions on the microstructure and tensile strength of aluminium alloy 6063," Materials Science Forum, vol. 396-402, no. 2, pp. 1211-1216, 2002.

[7] G. Al-Marahleh, "Effect of heat treatment on the distribution and volume fraction of $\mathrm{Mg}_{2} \mathrm{Si}$ in structural aluminum alloy 6063," Metal Science and Heat Treatment, vol. 48, no. 5-6, pp. 205-209, 2006.

[8] M. Cai, D. P. Field, and G. W. Lorimer, "A systematic comparison of static and dynamic ageing of two Al-Mg-Si alloys," Materials Science and Engineering A, vol. 373, no. 1-2, pp. 6571, 2004. 
[9] C. S. Tsao, C. Y. Chen, U. S. Jeng, and T. Y. Kuo, "Precipitation kinetics and transformation of metastable phases in Al-Mg-Si alloys," Acta Materialia, vol. 54, no. 17, pp. 4621-4631, 2006.

[10] G. Sha, K. O’Reilly, B. Cantor, J. Worth, and R. Hamerton, "Growth related metastable phase selection in a 6xxx series wrought $\mathrm{Al}$ alloy," Materials Science and Engineering A, vol. 304-306, no. 1-2, pp. 612-616, 2001.

[11] A. K. Gupta, D. J. Lloyd, and S. A. Court, "Precipitation hardening in Al-Mg-Si alloys with and without excess Si," Materials Science and Engineering A, vol. 316, no. 1-2, pp. 11-17, 2001.

[12] T. Nahoto, C. Fumyochi, S. Tomohisa, and F. Kouichiro, "Precipitation behavior of Al-Mg-Si tenary alloys," Materials Science Forum, vol. 217-222, pp. 815-820, 1996.

[13] A. Chennakesava and E. Zitoun, "Tensile behaviour of 6063/ $\mathrm{Al}_{2} \mathrm{O}_{3}$ particulate metal matrix composite fabricated by investment casting process," International Journal of Applied Engineering Research, vol. 1, no. 3, pp. 542-552, 2010.

[14] L. Karthikeyan and V. S. Senthil Kumar, "Relationship between process parameters and mechanical properties of friction stir processed AA6063- $\mathrm{T}_{6}$ aluminum alloy," Materials and Design, vol. 32, no. 5, pp. 3085-3091, 2011. 

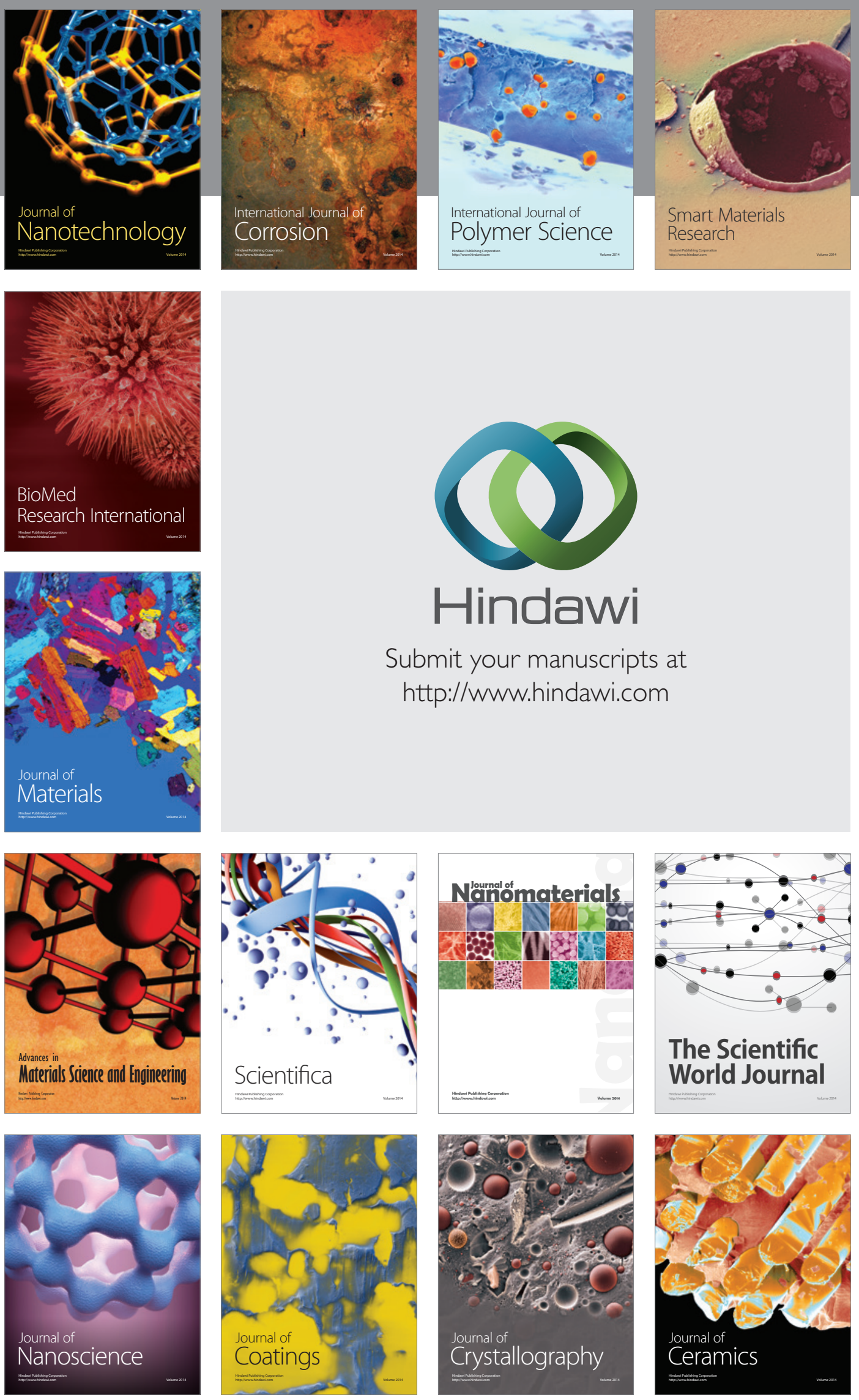

The Scientific World Journal

Submit your manuscripts at

http://www.hindawi.com

\section{World Journal}

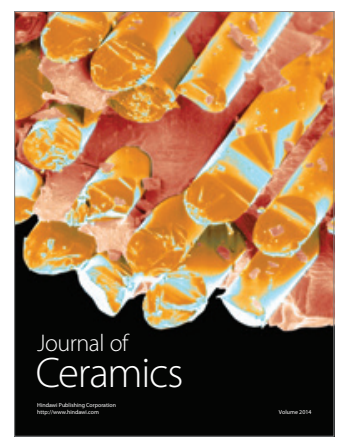

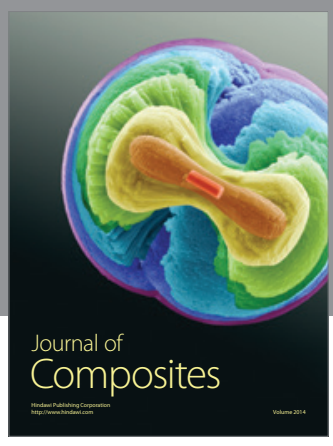
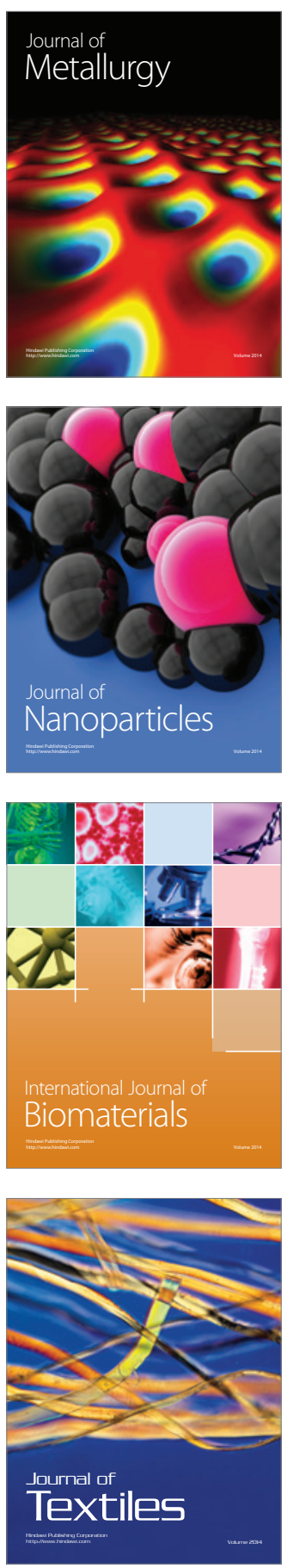